\title{
REAÇÕES DE PROFESSORAS EM CONTEXTOS DE EDUCAÇÃO CONTINUADA
}

\section{TEACHERS' REACTIONS IN CONTINUING EDUCATION CONTEXTS}

\author{
Márcia Regina do Nascimento SAMBUGARI*
}

Resumo: Este artigo apresenta alguns resultados de uma pesquisa sobre situações de socialização de professoras de $1^{\mathrm{a}}$ a $4^{\mathrm{a}}$ séries do Ensino Fundamental durante ações de educação continuada, analisadas com as categorias conceituais habitus e capital cultural, de Pierre Bourdieu. O estudo contou com observação em cursos de formação continuada, questionário e entrevistas. O texto apresenta o percurso teórico-metodológico da pesquisa e explicita tanto a contribuição de estudos sobre educação continuada, formação em serviço, como a perspectiva da socialização profissional do professor, a opção teórica utilizada e a discussão dos dados. As análises apontam que há modos de socialização mais freqüentes e diferentes contextos vivenciados pelas turmas dos cursos como elementos de interferência nas manifestações das professoras. Tais situações didáticas propiciam intensa interação, oportunizando atitudes de aceitação ou de rejeição manifestadas pelas professoras. As atitudes de rejeição não podem ser vistas apenas como manutenção do habitus pelas professoras, mas também como estratégias de luta por elas utilizadas para manutenção de seu capital simbólico. As atitudes de aceitação podem ser entendidas como possibilidades de reestruturação do habitus e ampliação do capital cultural. Com esse estudo buscou-se contribuir com novas perspectivas interpreta-

* Mestre em Educação Escolar pela Faculdade de Ciências e Letras de Araraquara/UNESP. Professora Assistente do Departamento de Educação do Campus do Pantanal/UFMS. Apoio Financeiro: CNPq. E-mail: marciasambugari@yahoo.com.br 
tivas para a educação continuada, pautadas na realidade do educador, nas características da escola, na valorização da experiência e na compreensão da coletividade.

Palavras-chave: Socialização. Educação continuada. Professoras

\begin{abstract}
This article presents some results from a research about the socialization situations of teachers from the 1 st to 4 th grades of Elementary Education during continuing education actions. The data was analyzed according to Pierre Bourdieu's conceptual categories of habitus and cultural capital. The study included the observation of continuing education courses, a questionnaire and interviews. The text presents the research theoretical-methodological framework and explicates the contribution of studies about continuing education, in-service education, the perspective of teachers' professional socialization, the theoretical option used and the discussion of the data. The analyses suggest that there are ways of socialization that are more frequent and different contexts experienced by the groups of teachers as elements of interference in teachers' manifestations. Such didactical situations provide intensive interactions which lead to attitudes of acceptance or rejection by teachers. The attitudes of rejection can not be seen only as the maintenance of teachers' habitus but also as struggle strategies used by teachers to maintain their symbolic capital. The acceptance attitudes can be understood as possibilities of restructuring the habitus and broadening of cultural capital. With this study we tried to contribute with new interpretative perspectives for continuing education based on the educators' reality, on the school characteristics, on the valuing of experience and on the comprehension of the collectivity.
\end{abstract}

Keywords: Socialization. Continuing Education. Teachers. 


\section{INTRODUÇÃO}

As exigências da contemporaneidade, marcadas por várias mudanças e diversos processos, e os estudos sobre educação têm apontado na direção de que se impõe à escola a redefinição do seu compromisso social e pedagógico. Além disso, têm exigido que o professor também reflita sobre as suas opções teóricas e busque novas propostas à sua ação.

Por essas razões, tem sido intensificada a necessidade de que o professor esteja em constante formação, devido, por exemplo, às exigências da organização da escola em regime de ciclos e de progressão continuada, como se propõe na nova Lei de Diretrizes e Bases da Educação Nacional - LDB 9394/96, fazendo com que ele reflita sobre a sua ação pedagógica e sobre as suas concepções acerca do processo de ensino-aprendizagem.

A divulgação dos Parâmetros Curriculares Nacionais (PCNs) e a proposta de alfabetização pautada no construtivismo também constituem mudanças ocorridas nas últimas décadas, apresentadas como oportunidades para toda a comunidade educativa pensar sobre o processo educacional como um todo. Contudo, tais mudanças implicam um redimensionamento global da escola, que consiste não somente na aceitação, mas também na valorização das diferenças e, conseqüentemente, na reorganização do trabalho pedagógico do professor.

Essas mudanças demandam novo posicionamento do professor em sua prática docente. Espera-se que ele tenha consciência crítica do processo pedagógico de forma ampla e abrangente, não se restringindo apenas às dificuldades específicas do cotidiano, mas estabelecendo uma "relação dialógica" com os seus colegas, como sugere Nóvoa (1992, p. 26).

Por outro lado, as instituições educacionais brasileiras têm sido marcadas por uma busca de qualificação associada à intensificação de exigências sociais e legais relativas ao exercício da função docente. Entretanto, a preocupação com a formação docente, inicial ou continuada, não é algo novo. Ao longo dos anos, apesar de muitos esforços feitos pelos sistemas de ensino com o intuito de valorizar o aperfeiçoamento profissional e continuado dos professores, os estudos têm apontado a baixa eficácia e eficiência das referidas ações para alterar substantivamente as realidades educativas. 
Diante desse duplo argumento põe-se a questão central deste estudo: o que ocorre em tais cursos? Se há exigências sociais e legais, de um lado, se há oferta de outro, há que se entender a mediação dos processos. Como os professores atuam nas situações de educação continuada? Que modos de socialização são utilizados por eles durante tais ações?

Com base nesse contexto apresentado de modo resumido, o presente estudo foi realizado com a intenção de investigar professores em situações de formação contínua, focalizando a socialização entre pares. A socialização é um processo contínuo que não ocorre de forma tranqüila, pois, conforme salientam Tardif e Raymond (2002), é marcado por rupturas e continuidades. Assim, a educação continuada pode ser espaço propício para se investigar como se dá essa socialização entre os professores e compreender de modo ampliado o que está envolvido nesses cursos.

Dessa maneira, este artigo apresenta o percurso teórico-metodológico da pesquisa, explicitando a contribuição de estudos para delimitação da temática investigada, a opção teórico-metodológica utilizada e a discussão dos dados.

\section{EDUCAÇÃO CONTINUADA, FORMAÇÃO EM SERVIÇO E PERSPECTIVA DA SOCIALIZAÇÃO PROFISSIONAL DO PROFESSOR}

É possível verificar a incidência de estudos sobre formação continuada e formação em serviço, e mesmo sobre socialização, quando se focalizam os aspectos pedagógicos da docência. Em todos esses focos há muita preocupação com a mudança na atuação dos professores, principalmente após o início do seu exercício profissional, porém nenhum deles vem associando duas ou mais dessas facetas.

Assim, foi fundamental estabelecer certas relações entre esses focos, sobretudo porque alguns estudos apontam para a dificuldade de mudança de determinados esquemas que, relacionados à profissão, são constituídos ao longo da vida. Sugerem a possibilidade de ocorrerem manifestações dos professores em direção dessa dificuldade, durante as atividades de formação continuada, e momentos em que eles possam posicionar-se quanto às ações a serem desenvolvidas e à forma como podem ser veiculados os conhecimentos nessas ações.

No contato com esses estudos constatou-se que, nos últimos 
anos, a educação continuada vem sendo o foco de muitas pesquisas e discussões cujos temas giram em torno das diversas concepções de formação continuada e das análises de propostas sobre essa modalidade de formação. Também o papel dos professores e da pesquisa nos processos de formação docente tem passado por reflexões e discussões, dando-se ênfase ao processo crítico-reflexivo e ao processo de formação contínua, ou seja, aquele que acontece ao longo de trajetória profissional, preferencialmente no espaço escolar, em serviço. (ANDRÉ et al., 1999; BRZEZINSKI e GARRIDO, 2001; ZEICHNER, 1998).

Com relação às concepções de formação continuada, alguns estudos apontam que a educação continuada não pode ser considerada uma formação que se restringe apenas a ações de reciclagens pedagógicas, mas um processo contínuo de desenvolvimento profissional do professor, de valorização da reflexão e da coletividade, tendo a escola como espaço privilegiado para que essa formação se concretize e se torne capaz de articular todas as dimensões da profissão e propiciar mudanças na prática pedagógica. (CANDAU, 1997; MARIN, 1995; PORTO, 2000).

Esses estudos possibilitam pressupor que o modo de participação dos professores em cursos de educação continuada pode propiciar mudanças na sua forma de pensar ou agir. Mas, há também docentes cuja ação pedagógica geralmente não se altera, provavelmente devido às propostas permeadas nesses cursos. Segundo Garcia (1998), os professores têm crenças e concepções que os acompanham ao longo de sua formação e que influenciam sua prática educativa e seu modo de ver o ensino. Ou seja, eles têm referenciais iniciais que foram construídos e internalizados por meio das suas relações já na infância, na escolarização, e que influenciam sua visão acerca da profissão, sendo muito fortes nos professores, mesmo depois de formados (MARIN, 1996).

Esses referenciais iniciais certamente têm influência também na visão que o professor traz sobre os cursos de formação continuada e na forma como a socializa. Assim, a educação continuada coletivizada pode ser considerada espaço propício para se investigar como se dá a socialização entre professores. O desvendamento desse espaço e dessa socialização pode contribuir para a compreensão da profissionalização docente.

Nos estudos sobre formação em serviço, as discussões giram 
em torno das diferentes concepções (AQUINO e MUSSI, 2001); das análises de propostas de programas e de projetos, fora ou no interior das escolas, focalizando também a formação a distância como uma modalidade significativa na formação continuada do professor (NASCIMENTO, 1996); do papel da coordenação pedagógica e da coletividade (ARAÚJO, 2000). Mas também alertam sobre as condições que precisam ser dadas ao professor para que de fato a formação em serviço funcione e proporcione mudança em sua prática (GIOVANNI, 2003).

Esses estudos retratam a formação de professores nas diversas categorias e em contextos diferenciados, abordando questões importantes com relação à formação contínua. Entretanto, o aspecto da socialização profissional do professor não foi abordado, demonstrando a necessidade de se investigar como os professores interagem em tais situações.

Com relação à socialização profissional, foram poucos os estudos realizados no Brasil sobre esse tema. De modo geral, focalizaram a aprendizagem da docência de professores iniciantes e experientes, assim como a opinião desses professores sobre a socialização profissional. Mostraram também as influências ocorridas no desenvolvimento profissional dos docentes e o papel das instituições formadoras, a fim de que se pudesse perceber a contribuição dos cursos de formação na inserção e atuação do futuro professor. (LUDKE, 1994, 1996, 1998). Todavia, é importante lembrar que há necessidade de se estudar também o que ocorre durante a veiculação de informações aos professores nas ações de educação continuada.

Nessa mesma perspectiva da aprendizagem da docência, outros estudos com professores iniciantes focalizaram a organização escolar como aspecto relevante para a compreensão da socialização profissional dos professores iniciantes, por ser um espaço no qual eles desenvolvem várias estratégias para se socializarem (FREITAS, 2002). Ressaltaram também a necessidade de compreensão do processo de "aprender a ensinar", a fim de conhecer os processos vividos pelas professoras na aprendizagem da docência (NUNES, 2002); a identificação de problemas enfrentados pelos professores no início da docência, bem como suas crenças acerca da profissão (MARCELO GARCIA, 1991), ou o desenvolvimento de saberes de professores iniciantes e recém contratados, para explicitar que papel a formação inicial desempenha na formação desses professores que 
estão iniciando a docência (GUIMARÃES e SOUSA, 2004). Apenas um trabalho investigou o processo de socialização num contexto de formação continuada (CHAMON, 2003), mas o estudo centrou-se na discussão da trajetória pessoal e profissional de alguns professores e no processo de identificação desses professores com a profissão a partir de sua participação num programa de formação continuada.

Ao investigarem a socialização profissional, a preocupação dos autores citados estava no aspecto pedagógico dessa socialização, isto é, em saber como o professor aprende a ser professor e como ocorre a sua interação com a instituição de ensino na qual trabalha. Apesar de focalizarem apenas a socialização de professores iniciantes ou em serviço, centrando-se na aprendizagem da profissão, tais estudos permitiram perceber que há trocas de informações entre os professores. $\mathrm{E}$ as situações vivenciadas em cursos de formação continuada podem, sem dúvida, ser espaço fértil para essas trocas.

\section{OPÇÃO TEÓRICA: SOCIALIZAÇÃO NA PERSPECTIVA DE PIERRE BOURDIEU}

O contato com os estudos que abordam as perspectivas teóricas que influenciaram as pesquisas sobre socialização profissional do professor contribuiu para se perceber que ao investigar os modos de socialização utilizados por professores em situações didáticas de educação continuada, seria necessária uma sustentação teórica que não restringisse o processo de socialização apenas como adaptação do sujeito e sua adequação às exigências dos cursos, numa visão funcionalista. Nem tampouco se pretendeu dar atenção apenas ao processo de interação, tendo em vista apenas a subjetividade do indivíduo, numa perspectiva interacionista.

Era necessário pensar num processo de socialização enquanto mediação entre as "ações impostas" e a "liberdade do sujeito". Exigia pensar sobre a socialização como processo de interação entre pares, que se dá mediante ações e práticas que se atualizam, ou não, conforme as situações vivenciadas pelos sujeitos. Estes, por sua vez, buscam novas estratégias para aceitar, ou não, as propostas veiculadas nos cursos de educação continuada.

Nessa direção, o corpo teórico de Pierre Bourdieu contribuiu nas análises do presente estudo devido à possibilidade de se pensar o quanto as ações das pessoas são atualizadas e transformadas (ou 
não), a partir das relações sociais que elas praticam ou praticaram, estabelecidas em determinadas situações, num processo permanente de interação.

Zeichner e Gore (1990, p. 331) situaram os estudos de Pierre Bourdieu dentro da perspectiva crítica. Atkinson e Delamont (1985, p.315), ao abordarem algumas tendências potenciais para o desenvolvimento de pesquisas sobre a socialização do professor, salientaram, entre outros autores, a contribuição da Sociologia de Pierre Bourdieu sobre a socialização profissional a partir dos conceitos de "habitus" e "capital cultural".

Dessa maneira, o conceito de socialização a partir da categoria habitus, de Bourdieu, foi tomado como referência. A socialização foi entendida na presente pesquisa como um processo de percepções e de práticas do sujeito que podem se alterar, ou não, dependendo das situações e interações vivenciadas pelo professor. O processo de socialização dentro dos cursos de formação continuada pode ser analisado sob esta ótica porque o professor age e interage constantemente nas situações didáticas que vivencia, manifestando atitudes de aceitação ou rejeição diante dessas circunstâncias vivenciadas.

A socialização é um processo de interação entre os membros de um grupo de valores, de crenças de uma determinada cultura que, a partir de experiências vividas pelos sujeitos, vão sendo alteradas, ou não. Assim sendo, no que se refere à docência, pode-se afirmar que o professor partilha de manifestações da cultura na escola - que são constituídas de valores, conflitos e tensões - com as quais interage constantemente. Entretanto, a forma com a qual irá se relacionar vai depender das disposições que foram sendo adquiridas por ele no decorrer de sua trajetória, pois:

A cultura não é apenas um código comum, nem mesmo um repertório comum de respostas e problemas recorrentes. Ela constitui um conjunto comum de esquemas fundamentais, puramente assimilados, e a partir dos quais se articula, segundo uma "arte da invenção" análoga à da escrita musical, uma infinidade de esquemas particulares diretamente aplicados a situações particulares (...). A relação que um indivíduo mantém com sua cultura depende, fundamentalmente, das condições nas quais ele a adquiriu, mormente porque o ato de transmissão cultural é, enquanto tal, a atualização exemplar de um certo tipo de relação com a cultura. (BOURDIEU, 1974, p.208-209; 219). 
No entanto, o autor salienta que o processo de socialização não ocorre de forma linear, somente através da incorporação dos valores do grupo de pertencimento, nem o agente socializado é objeto passivo das condições socializadoras. Isso quer dizer que os professores podem manifestar maneiras diferentes de pensar, bem como diferentes reações durante as situações vivenciadas nos cursos de educação continuada, a partir das condições de existência vivenciadas, isto é, do habitus de cada um, revelando um terreno fértil para se investigar como ocorre esse processo.

Para Bourdieu (2003, p. 53-54), habitus é um 'sistema de disposições duráveis', isto é, um conjunto de tendências, de comportamentos que vão sendo adquiridos pelo indivíduo por meio das experiências práticas e das 'condições materiais de existência', que são os preceitos, os conceitos, as preocupações produzidas primeiramente nas relações familiares e, posteriormente, nas demais agências de socialização com as quais ele irá se deparar no decorrer de sua vida, tais como a escola, clubes, igreja, vida profissional, etc. Essas disposições orientam as atitudes, as opções, enfim, as ações do indivíduo em seu agir cotidiano, que pode ser ora consciente ora inconsciente, e que está em constante reformulação.

Essas disposições duradouras vão se formando no decorrer da trajetória de vida de cada professor, a partir do "capital cultural", ou seja, das práticas culturais que vão formando a identidade, a percepção desses professores, evidenciando práticas próprias da camada social a que pertencem.

A noção de "Capital Cultural", elaborada por Bourdieu (2002, p. 74), refere-se aos códigos culturais, aos saberes ou bens culturais que o indivíduo vai adquirindo e à relação que ele mantém com esses conhecimentos. Apresenta-se na forma "incorporada", a partir da aquisição e internalização de conhecimentos, crenças e cultura; na forma "objetivada", por meio da aquisição de bens culturais; e na forma institucionalizada", que se dá por meio da certificação escolar.

Esse conceito, articulado à noção de habitus, contribuiu com o presente estudo no sentido de pensar sobre os cursos de formação continuada como possibilidades de ampliação do "capital cultural" dos professores e pensar sobre as situações didáticas, nos cursos, como as condições concretas para adquiri-lo.

O habitus pode ser considerado como um processo de interiorização das regularidades do "jogo social”, que vão sendo determinadas 
pelas situações em que o indivíduo está inserido. É necessário que se conheçam, portanto, essas regularidades, a fim de que se possa jogar numa determinada situação. Para que o indivíduo saiba como praticar o “jogo social”, é necessário que ele perceba quais são as regularidades, pois são elas que irão determinar as estratégias a serem utilizadas, uma vez que o habitus "é gerador de estratégias que podem ser objetivamente afins aos interesses objetivos de seus autores sem terem sido expressamente concebidas para este fim" (BOURDIEU, 1983, p. 94).

Para Bourdieu (1983, p. 93), estratégias são “ações objetivamente orientadas em relação a fins que podem não ser os fins subjetivamente almejados". Essa categoria também ofereceu pistas de análise ao se pensar nas interações dos professores enquanto processos de incorporação do "sentido do jogo", ou seja, de diferentes formas de manifestação e atuação dentro dos cursos de formação continuada, buscando estratégias seja para manter, seja para mudar a sua visão, a sua prática e a de seus pares.

Esses conceitos contribuíram para se pensar e analisar como ocorre a socialização do professor em situações de educação continuada, trazendo alguns questionamentos acerca dos cursos que vêm sendo oferecidos aos professores da rede pública de ensino, apontando a necessidade de se levar em conta os aspectos que fazem parte das condições de vida desses professores.

\section{ESTUDO PRELIMINAR: PRIMEIRAS APROXIMAÇÕES}

O estudo preliminar foi de suma importância, pois foram feitos os contornos necessários, contribuindo-se para a definição do referencial teórico utilizado. A definição das categorias conceituais do habitus e do capital cultural de Bourdieu pareceram adequadas. Como instrumentos de coleta de dados, tal estudo contou com a realização de entrevistas com cinco professores que atuavam nas séries iniciais do Ensino Fundamental, em uma escola da rede estadual, localizada em cidade da região oeste de Mato Grosso do Sul. Contou também com a utilização de questionário para caracterização dos participantes e com algumas sessões de observação numa situação de formação continuada.

Esse primeiro estudo empírico permitiu observar que os cursos de formação continuada eram importantes para a socialização dos 
professores, pois havia uma relação de troca entre eles, e que cada um desses cursos poderia ser considerado como um espaço de socialização que possibilitaria, ou não, alterar as atitudes, as ações dos professores. A primeira hipótese foi assim construída, considerando-se a educação continuada como organizadora de situações de socialização profissional que ocorre em duas vias: ao mesmo tempo em que veicula novos conhecimentos a serem incorporados pelos professores, buscando alteração de suas práticas pedagógicas, a educação continuada é também um espaço de interação e de trocas no qual eles se expressam, demonstrando atitudes de aceitação ou de rejeição diante das novas situações que vão sendo disseminadas entre eles.

Tais atitudes levaram à elaboração de outra hipótese: a de que, de um lado, existem disposições duradouras incorporadas nos professores, ou seja, habitus que comandam a sua visão sobre os temas veiculados nas ações de formação continuada, levando-os a modos de socialização que acabam afetando a interpretação e assimilação de novas informações. Mas, por outro lado, também podem existir outras disposições que vão se alterando, se reestruturando a partir das relações no grupo.

O estudo preliminar confirmou a relevância do estudo, assim como trouxe pistas para a utilização do conceito de socialização a partir da categoria conceitual de habitus. Ou seja, a incorporação de formas de pensar e agir duradouras, que engendram as ações dos professores contrapondo-se às exigências das ações de educação continuada, poderiam levar, ou não, à alteração do habitus no que se refere às facetas da docência.

\section{ESTUDO DEFINITIVO: O CAMINHO PERCORRIDO}

O estudo definitivo foi realizado na rede municipal de uma cidade localizada na região centro-oeste do estado de São Paulo, que permitiu o acompanhamento em cursos, observando os encontros e coletando outras informações por meio de entrevista e questionário.

As sessões de observação foram realizadas em seis turmas de dois cursos de formação continuada, sendo três turmas do Programa de Desenvolvimento Profissional Continuado - "Parâmetros em Ação" e três do Programa de Formação de Professores Alfabetizadores - "PROFA", totalizando 55 participantes. No decorrer das sessões de observação, cada participante e as formadoras receberam um 
questionário para caracterização das turmas e das professoras sobre suas condições de vida. A fim de complementar os dados, o estudo contou também com entrevistas com as três formadoras responsáveis pelas turmas dos cursos e oito professoras que foram selecionadas no decorrer das sessões de observação, a partir de manifestações de aceitação e de rejeição com relação aos cursos.

Os dados coletados foram organizados a partir de duas chaves de análise: "atitudes de aceitação" e "atitudes de rejeição".

\section{ALGUMAS CONSTATAÇÕES E DISCUSSÕES}

Com relação ao perfil das professoras participantes dos cursos foi possível verificar que o corpo docente da rede municipal da pequena cidade na qual a pesquisa foi desenvolvida, com 30.379 habitantes, é composto por profissionais oriundas da mesma fração de classe em que se declararam como média baixa. Quando se analisa essa população-alvo dos cursos, ou seja, essa parte significativa do corpo docente da rede municipal, verifica-se que a maioria da professoras tem renda relativamente baixa. Várias delas têm maridos desempregados; outras são partícipes de famílias de origem rural, com pais e avós exercendo atividades manuais; algumas são casadas com funcionários públicos, em geral com baixa escolaridade; muitas delas vêm de famílias com muitos filhos.

Um dado que chamou a atenção sobre o contexto profissional foi o número de professoras fazendo o curso relacionado à alfabetização, embora responsáveis pelas $3^{\mathrm{a}}$ e $4^{\mathrm{a}}$ séries no momento em que o processo de formação continuada em alfabetização estava acontecendo. É um sintoma da vivência das professoras nas realidades escolares e das trajetórias não bem sucedidas do alunado diante das políticas implantadas no Ensino Fundamental, como vêm denunciando vários estudos (DELGADO, 2004; KNOBLAUCH, 2004; TRUZZI, 2000).

Outro dado que merece destaque é o relativo ao número de professoras, as quais, além de fazerem os cursos, às vezes dois deles, atuavam em mais de uma escola: acima de 30\% delas tinha essa sobrecarga.

Com as análises ficou constatado que os modos de socialização mais utilizados pelas professoras foram os cochichos, a troca de olhares, as brincadeiras, a partir muitas vezes de piadinhas, em tom de ironia, manifestando certas regularidades de rejeição ou de aceitação 
ao que era proposto nos cursos.

Os momentos de interação mais recorrentes entre as professoras com atitudes de rejeição ocorreram principalmente na ausência das formadoras responsáveis pelos cursos, durante a cópia da "pauta" dos encontros, nas exibições dos vídeos do PROFA, nos trabalhos realizados em grupos ou individualmente, e durante a explanação das formadoras. Já as professoras com manifestações de aceitação conversavam entre si nos momentos de explanação e discussão com as formadoras, e nos trabalhos em grupos. É possível verificar que as atitudes de rejeição ou de aceitação aconteceram em diferentes contextos: as manifestações de rejeição estiveram mais presentes nas situações fora do controle estrito das formadoras, enquanto que as manifestações de aceitação ocorreram principalmente em momentos ou situações mais visíveis às formadoras, portanto sob controle. Esse dado pode ensejar a existência de situações falsificadas, porém os diálogos flagrados, registrados e analisados no decorrer da pesquisa pareceram adequados quanto ao seu real interesse.

As situações recorrentes nos dois cursos, com relação às manifestações das professoras sinalizando certa indisposição diante de temas e procedimentos de estudo, fizeram-nos retomar uma das hipóteses iniciais da presente pesquisa, destacando que talvez essa rejeição ocorresse devido a percepções, modos de pensar e agir incorporados nas professoras, afetando suas ações. Mas também foi apontado na análise que as atitudes de rejeição das professoras nos cursos não poderiam ser compreendidas apenas como manutenção de seu habitus anterior, mas também como estratégias de luta utilizadas para manutenção de seu capital simbólico, pois elas não são passivas, mas pessoas que se posicionam diante das situações vivenciadas.

Dessa maneira, é importante compreender as manifestações das professoras, levando em consideração suas condições de existência, pessoal e profissional. Elas tinham uma reputação a manter para sua sobrevivência e a de seus familiares. Eram de origem simples e continuavam trabalhando, embora em funções mais prestigiadas socialmente, sobretudo no município em que viviam com as características agrícolas bem marcadas. Aliás, como boa parte dos municípios brasileiros.

No que tange às professoras com atitudes de aceitação ficou bem caracterizada a possibilidade da incorporação do capital cultural escolar dos cursos, possibilitando a alteração do habitus, sobretudo 
no que se refere às noções revistas ou aprendidas e aos procedimentos a serem utilizados no dia-a-dia.

Tanto a estrutura dos cursos quanto os depoimentos das professoras apresentaram uma ênfase na prática enquanto "aplicação imediata da teoria", apontando a necessidade de os cursos levarem em conta as condições de existência do professor, a fim de compreender suas estratégias de socialização dentro desses contextos.

$\mathrm{Na}$ busca da compreensão ampliada sobre essa aceitação é possível pensar que talvez o filtro da prática, que perpassou muitos depoimentos dessas professoras ao dizerem que "a teoria tem que ser aplicada", possa estar relacionado com a etapa profissional da vida delas, pois, conforme observado nos dados obtidos sobre o tempo de atuação da docência, a maioria das professoras participantes dos cursos era estável, com uma média de dez a 17 anos de experiência. Segundo Huberman (2000), o desenvolvimento profissional do professor é um processo e cada ciclo vivenciado constitui-se por características próprias daquela situação, o que requer necessidades formativas específicas daquele momento.

Dessa maneira, talvez a valorização dada às situações do dia a dia, às várias formas de se trabalhar, esteja atrelada ao momento, à fase que elas viviam, denominada por Hubermam como "fase de diversificação". Para o autor, nessa fase "as pessoas lançam-se, então, numa pequena série de experiências pessoais, diversificando o material didático, os modos de avaliação, a forma de agrupar os alunos, as seqüências do programa, etc.” (HUBERMAN, 2000, p. 41), buscando alternativas após a fase inicial de aquisição de segurança e domínio das situações escolares.

Não se pode descartar, entretanto, a estrutura dos cursos como estava posta, ou seja, no favorecimento da incorporação dessa visão da teoria enquanto base para aplicação imediata na prática, pelas professoras. Essa sim, provavelmente, foi uma característica aceita por estar em conformidade com o habitus já implantado (desde a formação inicial), num padrão bem familiar de estudo e trabalho.

A análise dos modos de socialização entre as professoras durante as atividades permitiu verificar que as atitudes tiveram certas regularidades, com algumas professoras mais propensas a aceitá-las e outras mais inclinadas a atitudes de rejeição. Uma análise mais detalhada do conjunto dos episódios permite apontar regularidades, porém não constância total, pois tanto umas quanto outras professoras 
oscilaram em suas manifestações. Não havia, portanto, homogeneidade nessas manifestações; a homogeneidade ocorreu nas atitudes de constantes trocas entre elas.

Esse dado parece ser um indicador da condição de sujeitos que as professoras possuíam. Em certas situações de sala de aula elas aceitavam os procedimentos de estudo e as noções veiculadas - por estarem mais de acordo com seu habitus ou por identificarem condições de melhoria em suas atividades de docência. Ou, ainda, pelo fato de ter relato de uma colega, ao pé do ouvido, apontando o sucesso em circunstância similar.

Em outras situações didáticas as professoras rejeitavam perspectivas de trabalho ou conceitos, por se verem confrontadas em seu habitus ou pelas impossibilidades advindas das condições adversas em que viviam e atuavam. Nesses casos, as piadinhas e ironias eram constantes.

Essa oscilação de atitude entre as professoras foi um dado intrigante durante as análises. Se as que rejeitavam perspectivas de trabalho, às vezes também as aceitavam parcialmente - e o contrário também ocorria - qual era a possibilidade de compreensão de tais dados, se o conjunto das informações sobre elas e suas famílias eram tão similares? O que as teria levado a essa diferenciação de atuação?

Retomando o perfil geral dessas professoras, as suas condições de vida, a sua escolarização e experiência profissional, não é possível considerá-las como elementos de interferência, uma vez que não apresentaram muitas diferenças. No entanto, ao observar o contexto de cada grupo nos cursos em que as professoras estavam inseridas, talvez um elemento de interferência sejam as variáveis situacionais, experienciais e comunicativas, que são singulares em cada turma. Dependendo da turma, por um lado, as professoras vivenciaram situações didáticas em condições favoráveis como: turmas maiores, participativas, levando a uma perspectiva de contexto com comentários mais favorecedores à aceitação. Por outro lado, as professoras que apresentaram maior regularidade de rejeição freqüentaram os cursos em condições adversas como o frio, turmas pequenas, realização pela manhã, período em que os cochichos eram constantemente desfavoráveis a um resultado positivo.

Buscando ampliar as possibilidades relacionais com contextos mais amplos, há que se pensar, ainda, que pode haver outros tipos de interferência atuantes sobre as professoras, pois as diferentes 
esferas de contexto constituem cenários plurais em que elas estavam e ainda estão envolvidas.

Levar em conta essas "disposições", essas "estruturas incorporadas" pelas professoras é muito importante para entender como os modos de socialização e de troca vão ocorrendo dentro dos cursos. Porém, esse é um dado não considerado como elemento de interferência para o aproveitamento, ou não, na realização dos cursos. Dessa maneira, os cursos de formação continuada precisariam estar atentos a essa realidade das professoras e, talvez, a atenção à interação que elas fazem entre si possa trazer pistas para se repensar os cursos de formação continuada, para que sejam pautados a partir das necessidades, expectativas e condições concretas dos professores, de modo a contribuir para seu desenvolvimento profissional.

As análises das situações de interação entre as professoras, tanto com atitudes de aceitação quanto de rejeição, mostraram também que os cursos estão empobrecidos não porque sejam ruins. Ao contrário: eles ensinam a alfabetizar ou trabalham com conteúdos específicos da Matemática e para isso recuperam os conceitos, os procedimentos. No decorrer de sua realização, entretanto, limitam-se apenas a leituras, à aplicação em sala de aula e ao retorno para ver se tudo deu certo. As situações ou ocorrências positivas da sala de aula na maioria das vezes não têm, de fato, espaço para aparecer num debate mais amplo e coletivo, porque quando a professora vai aplicar uma atividade na sala de aula, provavelmente ela poderá enfrentar alguns tipos de dificuldades, alguns resultados não previstos, e isso acaba não aparecendo para a troca e o enfrentamento.

A análise de tais situações e modos de socialização permitiu, mais uma vez, verificar as realidades conflituosas vividas pelas professoras diante da implantação das reformas. Elas expressam em muitas das situações, a seu modo, o conflito instaurado em suas vidas profissionais em face das mudanças radicais exigidas delas. Durante muitas situações didáticas dos dois cursos de educação continuada elas tiveram a oportunidade para manifestações.

As constatações da presente pesquisa levaram-nos a reafirmar a hipótese inicial de que a educação continuada é um espaço de formação e socialização, ocorrendo, portanto, em duas vias: como espaço de veiculação de novos conhecimentos a serem incorporados pelos professores, abrindo a elas a possibilidade de ampliar seu capital cultural, e também como espaço de interação, de trocas, no qual os 
professores expressam sua visão, seja de aceitação - e aí parcialmente incorporando idéias, conhecimentos, para alterar seu habitus - seja de rejeição diante das situações que vão sendo apresentadas e, portanto, alterando pouco, ou nada do seu habitus.

Entretanto, é preciso acrescentar que as condições, o contexto das turmas também precisam ser levados em conta, pois são fundamentais para a compreensão das manifestações dentro desse espaço de formação, assim como as possibilidades de investigação que ficam abertas, principalmente as trajetórias profissionais. Afinal, ter atitudes de aceitação e de rejeição é normal; segundo a abordagem teórica deste estudo, ambas são aprendidas dentro das possibilidades postas pelas situações vividas e pelo espaço limitado, porém real, de subjetividade que cada professora possui para a constituição e alteração do habitus nos processos de formação e nas ações docentes.

\section{CONSIDERAÇÕES FINAIS}

As análises desenvolvidas neste trabalho acerca das reações de professoras em contextos de educação continuada constituíram uma tentativa de contribuir com novas perspectivas interpretativas para a educação continuada, pautada na realidade do educador, nas características da escola, na valorização da experiência e na compreensão da coletividade.

Com relação aos cursos de formação continuada, observa-se que, de um lado, eles cumpriram sua função técnica, porque as professoras aprenderam alguma coisa sobre a alfabetização ou sobre determinados conteúdos, ou ampliaram sua visão sobre determinados assuntos presentes nos Parâmetros Curriculares Nacionais (PCNs). Por outro lado, do ponto de vista dos saberes culturais, em que esses cursos têm contribuído para que as professoras ultrapassassem suas desvantagens culturais?

As análises apontaram que, da forma como estão organizados, esses cursos não estariam cumprindo esse papel mais reestruturador das atividades docentes que desempenhavam. Dessa maneira, assistimos a um empobrecimento dos cursos de formação continuada, principalmente por conta da racionalidade técnica, pois temos um formato que ignora o perfil, as necessidades formativas e culturais das professoras, impondo a elas uma metodologia basicamente com a mesma estrutura: "explanação, as professoras ouvem, fazem as 
leituras e vão aplicar o que aprenderam em sala de aula”. Reportando ao referencial teórico utilizado na presente pesquisa, parece que essa lógica que permeia tais cursos pode ser considerada, tal como a visão de escola em Pierre Bourdieu, como mais um dos fatores eficazes na conservação social. Segundo Bourdieu (1998, p. 41):

É provável por um efeito de inércia cultural que continuamos tomando o sistema escolar como um fator de mobilidade social, segundo a ideologia da "escola libertadora", quando, ao contrário, tudo tende a mostrar que ele é um dos fatores mais eficazes de conservação social, pois fornece a aparência de legitimidade às desigualdades sociais, e sanciona a herança cultural e o dom social tratado como dom natural.

Tudo indica que esses cursos, da forma como funcionam, se constituem em mais um fator de manutenção que de transformação, contribuindo para que tudo permaneça com está. Aqueles que planejam e executam os cursos de formação têm a intenção declarada de trazer mudanças, seja de concepção, seja no comportamento das professoras, mas muitas vezes ocorre o contrário, pois a própria forma como funcionam faz com que o efeito seja inverso.

Ao ignorar a realidade das professoras cursistas, que são produtos de uma desigualdade cultural, seja na história de vida familiar de cada uma, seja nas suas oportunidades de estudo e de formação, seja nas condições de precarização do seu trabalho, os cursos reiteram procedimentos pedagógicos que legitimam essas desigualdades, aceitando-as como naturais. Essa situação suscitou o seguinte questionamento: será que não falta nesses cursos justamente o exercício de um processo de reflexão, de indagação dos professores acerca de suas próprias condições de formação e de trabalho?

É evidente que os professores precisam saber sobre as teorias e procedimentos de alfabetização; no entanto, o exercício de reflexão, de indagação a respeito das condições e do processo de alfabetização não está posto no material desses cursos. Os professores continuam a não aprender especificamente aquilo que pode permitir-lhes um entendimento crítico das situações, dos acontecimentos educacionais e sociais, ou seja, aprender a interrogar a realidade em que eles atuam e obter um tipo de informação, em fontes confiáveis, que lhes possibilitem relacionar posicionamentos éticos, morais e ter a sensibilização 
política que certos contextos, ações e situações exigem.

Infelizmente, as análises apontaram que esses cursos não se constituem numa oportunidade de fazer o professor relacionar as esferas política e pedagógica, o que suscita outra questão: será que não é essa articulação que está faltando nos cursos de formação continuada? Tudo indica que sim, pois, conforme salienta Giovanni (2003), sem algumas condições essenciais não há como se concretizar o potencial educativo e transformador nas ações de formação continuada.

\section{REFERÊNCIAS}

ARAÚJO, I. A. Educação continuada: traços, trilhas e rumos da coordenação pedagógica. 2001, 144 f. Dissertação (Mestrado em Educação) - Faculdade de Educação, Universidade de Brasília, Brasília, 2001.

ATKINSON, P.; DELAMONT, S. Socialization into teaching: the research which lost its way. British Journal of Socioloy Education, v. 6, n. 3, p 307-322, 1985.

ANDRÉ, M. E. A. et al. Estado da arte da formação de professores no Brasil. Educação e Sociedade, ano xx, n. 68, p. 301-309, dez.1999.

AQUINO, J. G; MUSSI, M. C. As vicissitudes da formação docente em serviço: a proposta reflexiva em debate. Educação e Pesquisa, São Paulo, v. 27, n. 2, p. 211-227, jul./dez.2001.

BOURDIEU, P. Economia das trocas simbólicas. São Paulo: Perspectiva, 1974.

. Questões de sociologia. São Paulo: Marco Zero, 1983.

BOURDIEU, P. Os três estados do capital cultural. In: NOGUEIRA, M. A.; CATANI, A. (Org.). Escritos de Educação. Petrópolis: Vozes, 2002. p. 7179.

.Esboço de uma teoria da prática. In: ORTIZ, R. A sociologia de Pierre Bourdieu. São Paulo: Olho d'água, 2003. p. 39-72.

BRASIL. Lei n ${ }^{\circ}$ 9394, de 20 de dezembro de 1996, Estabelece as Diretrizes e Bases da Educação Nacional. Diário Oficial da União, Brasília, 23 dez. 1996. p. 27833-27841.

CANDAU, V. M. F. Formação continuada de professores: tendências atuais. In: 1997. p. 51-68. . (Org.). Magistério: construção cotidiana: Petrópolis: Vozes, 
CHAMON, E. M. Q. O. A formação continuada e o processo de socialização profissional de professores. In: CONGRESSO BRASILEIRO DE SOCIOLOGIA, 11., 2003, Campinas. Sociologia e Conhecimento: além das Fronteiras - Caderno de Resumos. Campinas, 2003. p. 115.

DELGADO, A. Um estudo sobre práticas avaliativas no regime de progressão continuada: limites e possibilidades. 2004. Dissertação (Mestrado em Educação), Pontifícia Universidade Católica de São Paulo, São Paulo, 2004.

FREITAS, M. N. C. Organização escolar e socialização profissional de professores iniciantes. Cadernos de Pesquisa, São Paulo, n. 115, p. 155-172, mar. 2002.

GIOVANNI, L. M. O ambiente escolar e ações de formação continuada. In: TIBALLI, E. F. A.; CHAVES, S. M. (Org.). Concepções e práticas de formação de professores: diferentes olhares. Rio de Janeiro: DP\&A, 2003. p. 207-224.

GUIMARÃES, V. S.; SOUSA, L. F. E. C. P. A socialização profissional e o aprendizado da profissão docente. In: ENCONTRO NACIONAL DE DIDÁTICA E PRÁTICA DE ENSINO, 12., 2004, Curitiba. Anais... Curitiba, 2004. p. 1743-1753. 1 CD-ROM.

HUBERMAN, M. O ciclo de vida profissional dos professores. In: NOVOA, Antonio (Org.) Vidas de professores. Portugal: Porto, 2000. p. 31-61.

KNOBLAUCH, A. Ciclos de aprendizagem e avaliação de alunos: o que a prática escolar nos revela. Araraquara: JM, 2004.

LUDKE, M. A socialização profissional de professores. Caxambu: ANPED, 1994. mimeografado.

. Sobre a socialização profissional de professores. Cadernos de Pesquisa, São Paulo, n. 99, p. 5-15, nov. 1996.

LUDKE, M. Socialização profissional de professores: as instituições formadoras. Relatório Final de pesquisa. Rio de Janeiro: Universidade Federal do Rio de Janeiro, 1998. Disponível em: http://www.cfch.ufrj.br/nec/pesquisa2. html/. Acesso em: 08 jun. 2003.

GARCIA, C. M. Aprender a enseñar: um estúdio sobre el proceso de socialización de profesores principiantes. Madrid: Centro de Publicaciones del Ministério de Educación y Ciência, 1991.

. Formação de professores: o conhecimento sobre o aprender e ensinar.

Revista Brasileira de Educação, São Paulo, n. 9, p. 51-75, 1998.

MARIN, A. J. Educação continuada: introdução a uma análise de termos e concepções. Cadernos CEDES, Campinas, n. 36, p. 13-20, 1995. 
. Propondo um novo paradigma para formar professores a partir das dificuldades e necessidades históricas nessa área. In: REALI, Maria Aline; MIZUKAMI, M. G. N. Formação de professores: tendências atuais. São Carlos: EDUFSCar, 1996. p. 153-165.

NASCIMENTO, M. G. C. A. A escola como espaço de formação continuada de professores: análise de uma experiência. 1996, 132 f. Dissertação (Mestrado em Educação)- Pontifícia Universidade Católica do Rio de Janeiro, Rio de Janeiro, 1996.

NÓVOA, A. Os professores e sua formação. Lisboa: Dom Quixote, 1992.

NUNES, J. B. C. O processo de socialização na profissão docente. In: ENCONTRO NACIONAL DE DIDÁTICA E PRÁTICA DE ENSINO, 11., 2002, Goiânia. Anais... Rio de Janeiro: Multipolo, 2002, p. 01-24. 1 CD-ROM.

PORTO, Y. S. Formação continuada: a prática pedagógica recorrente. In: MARIN, A. J. (Org.). Educação continuada: reflexões e alternativas. Campinas: Papirus, 2000, p. 11-37. (Coleção Magistério: Formação e trabalho pedagógico).

TARDIF, M.; RAYMOND, D. Saberes, tempo e aprendizagem do trabalho no magistério. In: TARDIF, M. Saberes docentes e formação profissional. Petrópolis: Vozes, 2002. p. 56-111.

TRUZZI, E. A. Eles são analfabetos, como posso ensiná-los? A ruptura entre a $4^{\mathrm{a}}$ e a $5^{\mathrm{a}}$ série e seus professores. 2000, $153 \mathrm{f}$. Dissertação (Mestrado em Educação Escolar)- Faculdade de Ciências e Letras, Universidade Estadual Paulista, Araraquara, 2000.

ZEICHNER, K. M.; Tendências da pesquisa sobre formação de professores no Estados Unidos. Revista Brasileira de Educação. São Paulo, n. 9, p. 76-87, 1998.

ZEICHNER, K. M.; GORE, J. M. Teacher socialization. In: HOUSTON, W. R. (Ed.). Handbook of research on teacher education. New York: Macmillan, 1990. p. 329-348.

Encaminhado em: 07/08/07

Aceito em: 01/10/07 